\title{
Dietary sources of salt intake in adults and older people: a population-based study in a Brazilian town
}

\author{
Milena Sia Perin ${ }^{1, *}$, Marilia Estevam Cornélio ${ }^{1}$, Henrique Ceretta Oliveira ${ }^{1}$, \\ Thais Moreira São-João' ${ }^{1}$ Caroline Rhéaume ${ }^{2}$ and Maria-Cecília Bueno Jayme Gallani ${ }^{3}$ \\ 'School of Nursing, University of Campinas, Rua Tessália Vieira de Camargo 126, Cidade Universitária Zeferino \\ Vaz, Campinas - SP, 13083-887, Brazil: ${ }^{2}$ Faculty of Medicine, Laval University, Québec, QC, Canada: ${ }^{3}$ Faculty of \\ Nursing, Laval University, Québec, QC, Canada
}

Submitted 12 March 2018: Final revision received 10 0ctober 2018: Accepted 17 0ctober 2018: First published online 26 November 2018

\begin{abstract}
Objective: To assess salt intake and its dietary sources using biochemical and selfreport methods and to characterize salt intake according to sociodemographic and disease-related variables in a sample of the Brazilian population.

Design: Population-based cross-sectional survey.

Setting: Salt intake was assessed by biochemical ( $24 \mathrm{~h}$ urinary $\mathrm{Na}$ excretion) and self-report methods (sodium FFQ, $24 \mathrm{~h}$ dietary recall, seasoned-salt questionnaire, discretionary-salt questionnaire and total reported salt intake).

Participants: Adults and older people ( $n$ 517) aged $20-80$ years, living in Artur Nogueira, São Paulo, Brazil.

Results: Mean salt intake based on $24 \mathrm{~h}$ urinary $\mathrm{Na}$ excretion and total reported salt intake was 10.5 and $11.0 \mathrm{~g} / \mathrm{d}$, respectively; both measures were significantly correlated. Discretionary salt and seasoned salt were the most important sources of salt intake (68.2\%). Men in the study consumed more salt than women as estimated by $24 \mathrm{~h}$ urinary $\mathrm{Na}$ excretion $(11.7 v$. $9.6 \mathrm{~g}$ salt/d; $P<0.0001)$. Participants known to be hypertensive added more salt to their meals but consumed less salty ultra-processed foods. Waist circumference in both sexes and BMI were positively correlated with salt intake estimated by $24 \mathrm{~h}$ urinary $\mathrm{Na}$ excretion. In addition, regression analysis revealed that being a young male or having a high waist circumference was a predictor of higher salt intake.

Conclusions: Salt intake in this population was well above the recommended amount. The main source of salt intake came from salt added during cooking. Salt intake varied according to sex and waist circumference.
\end{abstract}

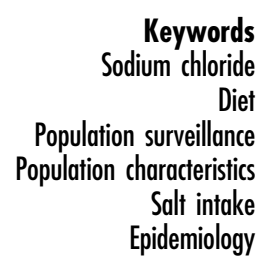

Nutritional factors increasingly contribute to the rise in CVD in the modern world. High salt intake associated with increased blood pressure is one of the important nutritional factors contributing to the development and worsening of $\mathrm{CVD}^{(1-6)}$. In addition, high-salt diets and low fruit and vegetable intakes were responsible for $10 \%$ of global disability-adjusted life years in 2010 and were the most prominent dietary risk factors globally and in twenty-one regions of the world ${ }^{(7)}$.

The estimated mean salt intake is about $10 \mathrm{~g} / \mathrm{d}$ worldwide, with regional variations ${ }^{(4,8,9)}$. This is well above the $<5 \mathrm{~g} / \mathrm{d}$ for all adults recommended by the $\mathrm{WHO}^{(10)}$.

Although many studies have raised controversy recently about the recommendations for establishing limits of salt intake for the general population ${ }^{(11,12)}$, estimating salt intake remains an important issue. Quantifying and recognizing the main sources of intake of salt among different populations and cultures is essential in identifying the need for intervention and targeting the relevant sources.

In Brazil, the few population-based studies on this topic used single methods to assess salt intake. For the example, a study conducted in a city in the state of Espírito Santo with 272 adults used only the $24 \mathrm{~h}$ urinary $\mathrm{Na}$ excretion method. The authors observed an average salt intake of $11.9 \mathrm{~g} / \mathrm{d}$ for men and $8.8 \mathrm{~g} / \mathrm{d}$ for women without, however, assessing intake sources ${ }^{(13)}$. Another study used data from the Brazilian Household Budget Survey (2008-2009), which is based on purchases of food for home use, and found that the individual amount of salt available in households was $11.7 \mathrm{~g} / \mathrm{d}^{(14)}$, although the data were not validated with an objective measure. 
Appropriate interventions aimed at promoting a healthier intake of dietary salt in the population requires knowledge about the intake quantity determined with a reliable, valid method ${ }^{(15-17)}$, as well as about the main sources of dietary salt and the typical frequency of their consumption ${ }^{(18)}$. Moreover, to the best of our knowledge, no Brazilian study has yet delineated the salt intake profile on a population basis, considering both self-reported and biochemical measures.

Therefore, the main objective of the present populationbased study was to assess the salt intake in a Brazilian adult sample according to biochemical $(24 \mathrm{~h}$ urinary $\mathrm{Na}$ excretion) and self-report methods. The secondary objective was to characterize the salt intake according to sociodemographic and disease-related variables.

\section{Methods}

The present study is a secondary analysis of a populationbased cross-sectional survey aimed at evaluating salt intake and testing its relationship with cardiometabolic risk factors in an adult and elderly population of a Brazilian town. All enrolled participants provided written informed consent and the local ethics committee approved the study.

\section{Participants}

The survey included adults and elderly people aged 20-80 years living in the town of Artur Nogueira ${ }^{(19)}$ (population: 51 126) in the state of São Paulo in the Southeast region of Brazil. We excluded individuals with chronic kidney or oncological diseases, communication issues and locomotor disabilities (bedridden, wheelchair-bound or lowerlimb paralysis of any type) as well as pregnant women.

We estimated the sample size according to Cochran's sample size formula for continuous data with a $95 \% \mathrm{CI}^{(20)}$. The calculation was based on data from Brazilian studies using $24 \mathrm{~h}$ urinary $\mathrm{Na}$ excretion to estimate salt intake $^{(21-23)}$. Thus, considering an SD of $5.8 \mathrm{~g}$ and a margin of error of $0.5 \mathrm{~g}$ within a $95 \% \mathrm{CI}$, the total estimated sample size was 517 participants.

\section{Sampling method}

The sampling procedure considered data from the family register in primary health-care centres in Artur Nogueira, where the public health system covers more than $80 \%$ of the population and the high accuracy of the register of families according to their respective territory makes it possible to track individuals, guaranteeing homogenization and sample representativeness. The number of participants from each of the ten primary health-care centres was proportionally distributed according to the number of persons registered in each centre. All household numbers from each centre were listed in a table in Microsoft ${ }^{\circledR}$ Excel version 13 and were randomized; the numbers drawn varied from thirty-three to sixty-five participants in the different centres.

\section{Procedures}

Data collection was carried out for each household selected; one of the researchers, the community health agent or the trained interviewer invited one participant from the household to participate in the research. If more than one participant was eligible, a person was selected by simple random sampling, using the lottery method. Then, the selected participant signed the consent form and the questionnaires on sociodemographic, disease-related data and salt intake were administered by the researcher or a trained interviewer. Participants were given written and verbal instructions for the $24 \mathrm{~h}$ urine collection at the end of the interview. They were advised to collect the urine in the provided container(s) over a full $24 \mathrm{~h}$ period. Urine collection was to start in the morning, discarding the first voiding and continuing collection until the following morning, including the first voiding of the second day. The container(s) were to be kept in the refrigerator until the urine was returned to the primary health-care centre within a maximum of two days after collection and then forwarded to the laboratory for analysis. The collection of the $24 \mathrm{~h}$ urine occurred within five days of the interview.

\section{Measurements}

\section{Participant characteristics}

Participants were characterized according to the following.

1. Sociodemographic data: age, sex, schooling, skin colour (white or not white, according to the classification proposed by the Brazilian Institute of Geography and Statistics), labour status (active or inactive), monthly family income and living condition (alone, with a partner, with children or partner, with children or others).

2. Self-reported disease-related variables: diabetes, dyslipidaemia (hypercholesterolaemia, hypertriacylglycerolaemia or mixed hyperlipidaemia according to the Brazilian Cardiology Society) ${ }^{(24)}$, stroke, coronary disease, hypertension, length of hypertension diagnosis, smoking and current alcohol use (considering all types of alcoholic beverage, regardless of the amount usually consumed in the last year).

3. Systolic and diastolic blood pressures: measured with the OMRON ${ }^{\circledR}$ HEM-742INT Digital Automatic Blood Pressure Monitor. The pressures were measured on the two upper limbs and repeated twice on the limb presenting the highest pressure value, with an interval of $1 \mathrm{~min}$ between measurements. The last measurement was considered ${ }^{(25)}$.

4. BMI: calculated from weight and height using the same Welmy 104A anthropometric scale model (maximum 
capacity of $150 \mathrm{~kg}$ and accuracy of $100 \mathrm{~g}$ ). All fieldworkers were trained and evaluated on these measurements.

5. Waist circumference: measured directly after the interview according to WHO recommendations ${ }^{(26)}$ (using an inelastic metric tape measure $2 \mathrm{~m}$ in length and marked in $0 \cdot 1 \mathrm{~cm}$ increments).

\section{Salt intake assessment}

Salt intake was assessed by biochemical and self-report methods.

Biochemical measure: $24 \mathrm{~h}$ urinary Na excretion. The biological measure of urinary excretion of $\mathrm{Na}$ over a $24 \mathrm{~h}$ period is considered the gold standard for quantifying salt intake. The ion-selective electrode $\operatorname{method}^{(27)}$ was used for urine analysis and performed using an AU680 Chemistry Analyzer (Beckman Coulter, Brea, CA, USA). The content of urinary $\mathrm{Na}$ in meq was converted into grams of salt, considering the molecular weight of $\mathrm{Na}(1 \mathrm{meq} \mathrm{Na}=$ $23 \mathrm{mg} \mathrm{Na}=0.058 \mathrm{~g}$ salt ${ }^{(28)}$. To verify completeness of the $24 \mathrm{~h}$ urine sample, participants recorded the start date/time and stop date/time of urine collection and any missed collections. Urine samples were discarded if the total volume was less than $250 \mathrm{ml}$ or in the case of self-reporting of missing (no more than a 'few drops') or spilled urine ${ }^{(29)}$.

Self-report method: $24 \mathrm{~h}$ dietary recall. Participants reported all foods and portion sizes consumed in the $24 \mathrm{~h}$ prior to the interview. The recall was done only at this point. After a participant reported a specific food or beverage, the portion size was estimated using a food model booklet or standard household measures, which allowed participants to accurately estimate portion sizes. Data were transferred to the Nutrition Data System for Research (NDSR) software (2015 version). The final amount of $\mathrm{Na}$ given by the dietary recall was the sum of the $\mathrm{Na}$ inherent in each of the foods consumed the previous day $(1 \mathrm{~g} \text { salt }=0.4 \mathrm{~g} \mathrm{Na})^{(28)}$. The Brazilian Table of Food Composition (TACO) ${ }^{(30)}$, which lists the composition of main foods in Brazil, was used for foods that were not present in the NDSR. Due to limited access to the NDSR software for a restricted period, a simple random sample scheme was performed using the software R 3.5.0 and a sub-sample of 319 out of the 517 recalls collected was analysed with the NDSR.

Self-report method: sodium FFQ. The sodium FFQ (NaFFQ), a tool developed and validated in a previous study $^{(31)}$ on the Brazilian population, comprises fifteen salty ultra-processed foods (ultra-processed food products are those that are ready to eat or ready to heat with little or no preparation) $)^{(32)}$ for which participants report their usual frequency of consumption and portion size in the preceding 6 months. The frequency is evaluated on a seven-point scale: (i) 'never'; (ii) 'less than once a month'; (iii) 'one to three times a month'; (iv) 'once a week'; (v) 'two to four times a week'; (vi) 'once a day'; and (vii) 'twice or more per day'. Portions are identified as small, medium or large, using the quantity relative to the average portion of each of the items as a reference. The Na content of foods was estimated in the original study ${ }^{(31)}$ with the TACO list; the amount of $\mathrm{Na}$ consumed is the sum of the product of intake frequency and portion for each food item. In our study, we used a reduced version of the NaFFQ with thirteen items (including lean ham, mortadella, pork sausage, chicken sausage, hotdog sausage, bacon, beef burger, feijoada, canned sardines, instant noodles (Miojo), burger (as fast food), pizza and snacks). Items mentioning the use of salt were evaluated separately.

Self-report method: discretionary-salt questionnaire. The discretionary-salt questionnaire (DSQ) was validated in a previous study ${ }^{(23,33)}$ on the Brazilian population. Participants reported the usual monthly salt consumption (number of $1 \mathrm{~kg}$ packages of salt consumed per month), the number of persons who ate meals at home, the age of each person and the number of meals that each person ate per week at home, to correct the salt consumption per person. Children younger than 3 years old were not considered in the calculation and the meals of children under 10 years of age were considered as half meals. The following steps were used to calculate the salt intake per person: (i) divide the amount of salt (grams) used per month at home by 30 and multiply the quotient by 7 (= grams of weekly salt intake at home); (ii) divide this amount of weekly salt intake by the total number of weekly meals (= grams of salt intake/meal); (iii) multiply the amount of salt used per meal by the number of meals eaten per week by the participant; and (iv) divide the total weekly salt intake of the participant by 7 , resulting in the estimated quantity of individual daily added salt.

Self-report method: seasoned-salt questionnaire. The seasoned-salt questionnaire (SSQ) was validated in a previous study ${ }^{(23)}$ on the Brazilian population. Participants were asked about the brand, quantity (cubes, packets) and frequency of use of industrialized salt seasonings. The $\mathrm{Na}$ content of each seasoned salt was obtained from the product label. Subsequently, the procedure for calculating discretionary salt was used.

Self-report method: total reported salt intake. Total reported salt intake is the sum of salt intake obtained by the measurements of the $24 \mathrm{~h}$ dietary recall, Na-FFQ, DSQ and SSQ. The sum was calculated only for the sub-sample of 319 participants for whom the $24 \mathrm{~h}$ dietary recall was assessed.

\section{Data analysis}

Initially, the Shapiro-Wilk test was used to check the normality of the continuous variables. Since these variables presented a non-normal distribution, descriptive analyses were used to characterize the sample according to sociodemographic and disease-related variables. A correlation test (Spearman) was used to assess the relationship of salt intake measures with continuous sociodemographic and disease-related variables. In addition, the Mann-Whitney 
$U$ test was used to compare the mean salt intake according to the sociodemographic and disease-related categorical variables. Lastly, multiple regression analyses using the generalized linear model approach were performed to explore the relationship of $24 \mathrm{~h}$ urinary $\mathrm{Na}$ excretion and total reported salt intake according to sex, age, monthly family income, waist circumference, hypertension and diabetes. We chose this class of models instead of the traditional linear regression because generalized linear models are less restrictive to the error term distribution ${ }^{(34)}$. The significance level adopted was 5\%.

\section{Results}

Table 1 provides the characteristics of the whole sample and the sub-sample of 319 participants included in analysis of the $24 \mathrm{~h}$ dietary recall. The mean age of participants was 53.5 years; $58.4 \%$ were women. The mean monthly family income was \$US 753.20; $42.9 \%$ lived with their children and partner. Almost half of the participants reported being hypertensive (44.5\%) and $15.1 \%$ reported they were diabetics.

Overall salt intake was almost the same considering $24 \mathrm{~h}$ urinary $\mathrm{Na}$ excretion and total reported salt intake: 10.5 and $11.0 \mathrm{~g} / \mathrm{d}$, respectively. As for sources of salt intake, $68.2 \%$ came from the DSQ and SSQ; $24.0 \%$ from the intrinsic $\mathrm{Na}$ assessed from $24 \mathrm{~h}$ dietary recall; and $7 \cdot 3 \%$ from ultra-processed foods with high salt contents assessed by the Na-FFQ (Table 1 ).

Table 2 gives the correlations between $24 \mathrm{~h}$ urinary $\mathrm{Na}$ excretion and the self-report methods. When the whole sample is considered, the total reported salt intake measure, the Na-FFQ and the SSQ presented significantly positive

Table 1 Sociodemographic and disease-related characteristics, blood pressure, anthropometric variables and salt intake in the study population of adults and older people $(n 517)$ aged 20-80 years, Artur Nogueira, São Paulo, Brazil, June-September 2016

\begin{tabular}{|c|c|c|c|c|c|c|c|c|}
\hline & \multicolumn{4}{|c|}{ Sub-sample of $24 \mathrm{~h}$ dietary recall $(n 319)$} & \multicolumn{4}{|c|}{ Overall study population ( $n 517)$} \\
\hline & Mean or $n$ & SD or $\%$ & Median & Q1-Q3 & Mean or $n$ & SD or $\%$ & Median & Q1-Q3 \\
\hline \multicolumn{9}{|l|}{ Sociodemographic variables } \\
\hline Age (years) & $52 \cdot 8$ & 13.9 & $54 \cdot 0$ & $43 \cdot 0-63 \cdot 0$ & 53.5 & $14 \cdot 1$ & $55 \cdot 0$ & $44 \cdot 0-65 \cdot 0$ \\
\hline Schooling (years) & $6 \cdot 7$ & 4.4 & $5 \cdot 0$ & $4.0-11.0$ & $6 \cdot 3$ & 4.4 & $5 \cdot 0$ & $3 \cdot 0-11 \cdot 0$ \\
\hline Family monthly income (\$US) & $812 \cdot 9$ & $823 \cdot 3$ & $645 \cdot 2$ & $387 \cdot 1-967 \cdot 7$ & $753 \cdot 2$ & $720 \cdot 6$ & $612 \cdot 9$ & $369.0-967.7$ \\
\hline Sex (women), $n$ and \% & 184 & $57 \cdot 7$ & & & 302 & 58.4 & & \\
\hline Skin colour (white), $n$ and \% & 164 & $51 \cdot 4$ & & & 264 & $51 \cdot 1$ & & \\
\hline \multicolumn{9}{|l|}{ Living condition, $n$ and $\%$} \\
\hline Alone & 37 & 11.6 & & & 58 & $11 \cdot 3$ & & \\
\hline With partner & 65 & $20 \cdot 4$ & & & 101 & 19.5 & & \\
\hline With children/partner & 134 & $42 \cdot 0$ & & & 222 & $42 \cdot 9$ & & \\
\hline With children/others & 83 & $26 \cdot 0$ & & & 136 & $26 \cdot 3$ & & \\
\hline Labour status (inactive), $n$ and \% & 216 & $67 \cdot 7$ & & & 367 & $71 \cdot 0$ & & \\
\hline \multicolumn{9}{|l|}{ Self-reported disease-related variables } \\
\hline Smoking, $n$ and $\%$ & 26 & $13 \cdot 1$ & & & 56 & $10 \cdot 8$ & & \\
\hline Alcohol consumption, $n$ and $\%$ & 64 & $20 \cdot 1$ & & & 104 & $20 \cdot 1$ & & \\
\hline Dyslipidaemia, $n$ and $\%$ & 60 & $30 \cdot 3$ & & & 157 & $30 \cdot 4$ & & \\
\hline Diabetes, $n$ and \% & 32 & $16 \cdot 2$ & & & 78 & $15 \cdot 1$ & & \\
\hline Hypertension, $n$ and \% & 99 & $50 \cdot 0$ & & & 230 & 44.5 & & \\
\hline Hypertension diagnosis length (years) & $11 \cdot 2$ & $9 \cdot 6$ & 8.0 & $3 \cdot 0-18 \cdot 0$ & $11 \cdot 3$ & $9 \cdot 7$ & $10 \cdot 0$ & $4 \cdot 0-18 \cdot 0$ \\
\hline \multicolumn{9}{|l|}{ Systolic blood pressure (mmHg) } \\
\hline Hypertensive† & $146 \cdot 2$ & 20.5 & $146 \cdot 5$ & $131 \cdot 5-159 \cdot 0$ & $145 \cdot 9$ & 21.5 & $145 \cdot 7$ & $131 \cdot 0-204 \cdot 0$ \\
\hline Normotensive & $127 \cdot 3$ & $17 \cdot 7$ & $126 \cdot 5$ & $115 \cdot 0-138 \cdot 0$ & $127 \cdot 7$ & $17 \cdot 2$ & $126 \cdot 5$ & $116 \cdot 0-138.5$ \\
\hline \multicolumn{9}{|l|}{ Diastolic blood pressure $(\mathrm{mmHg})$} \\
\hline Hypertensive† & 83.5 & $13 \cdot 1$ & $82 \cdot 0$ & $75 \cdot 0-90 \cdot 5$ & $83 \cdot 4$ & $12 \cdot 7$ & $82 \cdot 5$ & $75 \cdot 0-90 \cdot 5$ \\
\hline Normotensive & 77.4 & 11.4 & $76 \cdot 2$ & $69 \cdot 5-85 \cdot 0$ & 77.5 & 10.5 & $76 \cdot 5$ & $70 \cdot 0-85 \cdot 0$ \\
\hline $\operatorname{BMl}\left(\mathrm{kg} / \mathrm{m}^{2}\right)$ & 28.6 & $6 \cdot 1$ & $27 \cdot 9$ & $24 \cdot 7-31 \cdot 2$ & $28 \cdot 3$ & $5 \cdot 8$ & $27 \cdot 8$ & $24 \cdot 8-31 \cdot 0$ \\
\hline \multicolumn{9}{|l|}{ Waist circumference $(\mathrm{cm})$} \\
\hline Male & 99.2 & 11.4 & $100 \cdot 0$ & $92 \cdot 5-107 \cdot 0$ & 99.0 & $12 \cdot 1$ & $100 \cdot 0$ & $92 \cdot 0-107.0$ \\
\hline Female & 93.2 & $12 \cdot 8$ & 92.5 & $85 \cdot 0-100 \cdot 0$ & 93.6 & $12 \cdot 4$ & 93.0 & $86 \cdot 0-100 \cdot 0$ \\
\hline \multicolumn{9}{|l|}{ Salt intake $(g / d)$} \\
\hline \multicolumn{9}{|l|}{ Biochemical measure } \\
\hline $24 \mathrm{~h}$ urinary $\mathrm{Na}$ excretion & & & & & $10 \cdot 5$ & 4.5 & 9.8 & $7 \cdot 4-13 \cdot 0$ \\
\hline \multicolumn{9}{|l|}{ Self-reported methods } \\
\hline $24 \mathrm{~h}$ dietary recall ( $n 319$ ) & $2 \cdot 9$ & 2.5 & $2 \cdot 3$ & $1.4-3.6$ & & & & \\
\hline $\mathrm{Na}-\mathrm{FFQ}$ & 0.8 & $1 \cdot 1$ & 0.5 & $0 \cdot 2-1 \cdot 0$ & $0 \cdot 8$ & $1 \cdot 0$ & 0.5 & $0 \cdot 2-1 \cdot 0$ \\
\hline DSQ & 6.5 & $5 \cdot 2$ & $5 \cdot 6$ & $3 \cdot 3-8 \cdot 3$ & $6 \cdot 8$ & $5 \cdot 3$ & $5 \cdot 6$ & $3 \cdot 3-8 \cdot 3$ \\
\hline SSQ & 0.8 & 1.6 & 0.2 & $0-0.8$ & 0.7 & 1.5 & 0.1 & $0-0.8$ \\
\hline Total reported salt intake ( $n 319)$ & $11 \cdot 0$ & 5.9 & 9.7 & $7 \cdot 0-13 \cdot 1$ & & & & \\
\hline
\end{tabular}

Q1-Q3, interquartile range; Na-FFQ, sodium FFQ; DSQ, discretionary-salt questionnaire; SSQ, seasoned-salt questionnaire.

Data presented are mean, SD, median and Q1-Q3 for continuous variables; or $n$ and \% for categorical variables as indicated

†Hypertension defined as self-reported hypertension or use of antihypertensive medicine; present in $41.1 \%(131 / 319)$ of the sub-sample and $44.5 \%(230 / 517)$ of the overall study population. 
Table 2 Correlations between salt intake estimated by self-reported methods and the biochemical measure, according to sex, in the study population of adults and older people ( $n$ 517) aged 20-80 years, Artur Nogueira, São Paulo, Brazil, June-September 2016

\begin{tabular}{|c|c|c|c|c|c|c|c|c|c|c|}
\hline & \multicolumn{2}{|c|}{$\begin{array}{l}\text { Total reported salt intake } \\
\qquad(\text { (n 319) }\end{array}$} & \multicolumn{2}{|c|}{$\begin{array}{l}24 \mathrm{~h} \text { dietary recall } \\
(\text { ( } 319)\end{array}$} & \multicolumn{2}{|c|}{$\begin{array}{l}\text { Na-FFQ } \\
(n 517)\end{array}$} & \multicolumn{2}{|c|}{$\begin{array}{c}\mathrm{SSQ} \\
(n 517)\end{array}$} & \multicolumn{2}{|c|}{$\begin{array}{c}\mathrm{DSQ} \\
(n 517)\end{array}$} \\
\hline & $r$ & $P$ value & $r$ & $P$ value & $r$ & $P$ value & $r$ & $P$ value & $r$ & $P$ value \\
\hline \multicolumn{11}{|c|}{ 24h urinary $\mathrm{Na}$ excretion } \\
\hline Total sample & 0.192 & 0.001 & 0.110 & 0.051 & 0.222 & $<0.001$ & 0.106 & 0.016 & 0.070 & 0.110 \\
\hline Male & 0.057 & 0.512 & 0.148 & 0.087 & 0.221 & 0.001 & 0.062 & 0.367 & 0.015 & 0.823 \\
\hline Female & 0.263 & $<0.001$ & 0.034 & 0.651 & 0.191 & 0.001 & 0.174 & 0.002 & 0.128 & 0.026 \\
\hline \multicolumn{11}{|c|}{$24 \mathrm{~h}$ dietary recall } \\
\hline Total sample & & & & & 0.376 & $<0.001$ & -0.006 & 0.910 & -0.163 & 0.003 \\
\hline Male & & & & & 0.405 & $<0.001$ & 0.008 & 0.922 & -0.140 & 0.105 \\
\hline Female & & & & & 0.337 & $<0.001$ & 0.006 & 0.934 & -0.200 & 0.007 \\
\hline \multicolumn{11}{|l|}{ Na-FFQ } \\
\hline Total sample & & & & & & & 0.212 & $<0.001$ & -0.035 & 0.428 \\
\hline Male & & & & & & & 0.114 & 0.097 & -0.064 & 0.352 \\
\hline Female & & & & & & & 0.296 & $<0.001$ & -0.019 & 0.745 \\
\hline \multicolumn{11}{|l|}{ SSQ } \\
\hline Total sample & & & & & & & & & 0.029 & 0.510 \\
\hline Male & & & & & & & & & 0.080 & 0.245 \\
\hline Female & & & & & & & & & -0.013 & 0.828 \\
\hline
\end{tabular}

Na-FFQ, sodium FFQ; DSQ, discretionary-salt questionnaire; SSQ, seasoned-salt questionnaire, $r$, Spearman's correlation coefficient.

correlations with $24 \mathrm{~h}$ urinary $\mathrm{Na}$ excretion. Examining the correlations according to sex, all self-report measures, except the $24 \mathrm{~h}$ dietary recall, positively correlated with $24 \mathrm{~h}$ urinary Na excretion for women, but the correlation among men was significant only for the Na-FFQ.

Considering sociodemographic characteristics, we observed a higher salt intake according to $24 \mathrm{~h}$ urinary $\mathrm{Na}$ excretion among people under 65 years old, male, professionally active and with a higher family income. Specifically, regarding sex, men consumed more salt than women according to $24 \mathrm{~h}$ urinary $\mathrm{Na}$ excretion, $24 \mathrm{~h}$ dietary recall, Na-FFQ and total reported salt intake, but they were not different regarding salt added to meals. Participants who were professionally active and those with higher family incomes had a higher salt intake according to $24 \mathrm{~h}$ urinary $\mathrm{Na}$ excretion and the self-reported measures of $24 \mathrm{~h}$ recall and Na-FFQ. They reported, however, a lower use of discretionary salt in their meals (Table 3).

Participants who reported they were hypertensive and/ or diabetic had a lower intake of salty foods according to $\mathrm{Na}-\mathrm{FFQ}$ results and/or the $24 \mathrm{~h}$ dietary recall, but a higher intake according to the DSQ. Thus, total salt intake considering the sum of the self-reported methods or by $24 \mathrm{~h}$ urinary $\mathrm{Na}$ excretion - was equivalent whether the participants presented these diseases or not. Those reporting alcohol use, however, had significantly higher salt intake based on the biochemical measure, the $24 \mathrm{~h}$ dietary recall and the Na-FFQ (Table 4).

There was no correlation between either measure of total salt intake (24h urinary $\mathrm{Na}$ excretion or sum of selfreported methods) and blood pressure levels. In the total sample, however, systolic blood pressure correlated negatively with the $24 \mathrm{~h}$ dietary recall and Na-FFQ but correlated positively with the DSQ. In the case of diastolic blood pressure, we observed a positive correlation with the DSQ in the total sample and with the Na-FFQ among normotensive participants (Table 4).

For the anthropometric data, we observed positive correlations of $24 \mathrm{~h}$ urinary $\mathrm{Na}$ excretion with BMI and waist circumference for both men and women. For the self-report measures, waist circumference positively correlated only with the Na-FFQ among men and with the DSQ among women (Table 4).

Linear regression analyses (Table 5) indicated that being younger, male or having a higher waist circumference accounted for higher $24 \mathrm{~h}$ urinary $\mathrm{Na}$ excretion. The level of total salt intake given by the sum of the reported methods, however, was related solely to male sex.

\section{Discussion}

The results of the present study showed that the adult and elderly population of the town of Artur Nogueira has a daily salt intake, obtained by $24 \mathrm{~h}$ urinary $\mathrm{Na}$ excretion as well as by total reported salt intake, considerably higher than the value of $5 \mathrm{~g}$ salt/d recommended by the $\mathrm{WHO}^{(10)}$. Elevated daily salt intake has also been found in other developing countries such as India (with variations between the North and the South: 9.4 and $10.4 \mathrm{~g}$, respectively) ${ }^{(35)}$, China $(11 \mathrm{~g})^{(36)}$ and South Africa $(7 \cdot 2 \mathrm{~g})^{(37)}$, as well as in developed countries such as Australia $(9 \cdot 2 \mathrm{~g})^{(38)}$, Italy and Japan $(10 \cdot 6 \mathrm{~g})^{(36)}$.

Although many countries have high salt intake, the intake sources vary considerably, ranging from ultraprocessed foods and ready-to-eat foods to the salt added to food prepared in the home or added at the table $e^{(14,23,39-42)}$. In our sample, salt added during cooking and at the table, as evaluated by the DSQ and SSQ, were the primary intake sources. On the other hand, ultra- 
Table 3 Salt intake (mean and SD; g/d) according to sociodemographic variables in the study population of adults and older people ( $n 517$ ) aged 20-80 years, Artur Nogueira, São Paulo, Brazil, June-September 2016

\begin{tabular}{|c|c|c|c|c|c|c|c|c|c|c|c|c|}
\hline & \multicolumn{2}{|c|}{$\begin{array}{l}\text { Total reported salt intake } \\
\text { ( }(\text { 319) }\end{array}$} & \multicolumn{2}{|c|}{$\begin{array}{l}24 \mathrm{~h} \text { urinary } \mathrm{Na} \text { excretion } \\
\text { ( } n \text { 517) }\end{array}$} & \multicolumn{2}{|c|}{$\begin{array}{c}24 \mathrm{~h} \text { dietary recall } \\
(n 319)\end{array}$} & \multicolumn{2}{|c|}{$\begin{array}{l}\text { Na-FFQ } \\
(n 517)\end{array}$} & \multicolumn{2}{|c|}{$\begin{array}{c}\text { SSQ } \\
(n 517)\end{array}$} & \multicolumn{2}{|c|}{$\begin{array}{c}\mathrm{DSQ} \\
(n 517)\end{array}$} \\
\hline & Mean & SD & Mean & SD & Mean & SD & Mean & SD & Mean & SD & Mean & SD \\
\hline \multicolumn{13}{|l|}{ Age } \\
\hline$<65$ years $(n 386)$ & $10 \cdot 8$ & $5 \cdot 8$ & $10 \cdot 8^{*}$ & 4.6 & $3 \cdot 1^{\star \star}$ & $2 \cdot 7$ & $0.9^{\star \star}$ & $1 \cdot 1$ & $0.8^{*}$ & $1 \cdot 3$ & $6 \cdot 3^{\star}$ & 4.9 \\
\hline$\geq 65$ years & 11.4 & $6 \cdot 7$ & $9 \cdot 7^{\star}$ & 4.0 & $2 \cdot 0^{\star}$ & 1.7 & $0.5^{\star \star}$ & 0.6 & $0.7^{\star}$ & $2 \cdot 0$ & $8 \cdot 1^{*}$ & $6 \cdot 1$ \\
\hline \multicolumn{13}{|l|}{ Schooling } \\
\hline$\leq 5$ years $(n$ 287) & 11.1 & $6 \cdot 1$ & $10 \cdot 4$ & 4.4 & $2 \cdot 4^{\star \star}$ & $2 \cdot 7$ & $0.6^{\star *}$ & 0.7 & 0.7 & 1.2 & $7 \cdot 7^{\star \star}$ & $5 \cdot 7$ \\
\hline$>5$ years & $10 \cdot 9$ & $5 \cdot 8$ & $10 \cdot 6$ & 4.7 & $3 \cdot 5^{\star}$ & $2 \cdot 2$ & $1 \cdot 0^{\star \star}$ & 1.3 & 0.8 & 1.8 & $5 \cdot 7^{\star}$ & 4.5 \\
\hline \multicolumn{13}{|l|}{ Sex } \\
\hline Male & $12 \cdot 0^{*}$ & $7 \cdot 1$ & $11 \cdot 7^{\star \star}$ & 4.9 & $3 \cdot 3^{*}$ & 3.2 & $0.9^{*}$ & $1 \cdot 1$ & 0.8 & 1.8 & $7 \cdot 2$ & $6 \cdot 4$ \\
\hline Female (n 302) & $10 \cdot 2^{*}$ & 4.8 & $9 \cdot 6^{\star \star}$ & 4.0 & $2 \cdot 6^{*}$ & 1.9 & $0 \cdot 7^{*}$ & $1 \cdot 0$ & 0.7 & $1 \cdot 2$ & $6 \cdot 5$ & 4.3 \\
\hline \multicolumn{13}{|l|}{ Labour status } \\
\hline Active & $11 \cdot 2$ & $6 \cdot 7$ & $11 \cdot 5^{\star}$ & $5 \cdot 1$ & $3 \cdot 8^{\star \star}$ & 3.4 & $1.0^{\star \star}$ & 1.4 & 0.6 & 1.0 & $5 \cdot 9^{\star *}$ & $5 \cdot 6$ \\
\hline Inactive ( $n$ 367) & $10 \cdot 8$ & 5.5 & $10 \cdot 1^{*}$ & $4 \cdot 2$ & $2 \cdot 4^{\star \star}$ & 1.9 & $0.7^{\star \star}$ & 0.9 & 0.8 & 1.6 & $7 \cdot 2^{\star \star}$ & $5 \cdot 1$ \\
\hline \multicolumn{13}{|l|}{ Family monthly income } \\
\hline$\leq \$$ US $613.00(n 260)$ & 11.4 & 5.9 & $10 \cdot 1^{*}$ & 4.5 & $2 \cdot 4^{\star \star}$ & 1.8 & $0.7^{\star}$ & 0.9 & 0.8 & 1.8 & $7 \cdot 6^{\star}$ & 5.6 \\
\hline$>\$$ US 613.00 & $10 \cdot 5$ & $6 \cdot 0$ & $11.0^{*}$ & 4.5 & $3 \cdot 3^{\star \star}$ & 3.0 & $0.8^{*}$ & $1 \cdot 1$ & 0.6 & $1 \cdot 1$ & $5 \cdot 9^{*}$ & 4.8 \\
\hline
\end{tabular}

Na-FFQ, sodium FFQ; DSQ, discretionary-salt questionnaire; SSQ, seasoned-salt questionnaire, $r$, Spearman's correlation coefficient.

${ }^{*} P<0.05,{ }^{* *} P<0.0001$ (Mann-Whitney $U$ test).

Table 4 Salt intake (mean and SD; g/d) according to disease-related variables, and correlation of blood pressure and anthropometric variables with salt intake measures, in the study population of adults and older people $(n 517)$ aged $20-80$ years, Artur Nogueira, São Paulo, Brazil, June-September 2016

\begin{tabular}{|c|c|c|c|c|c|c|c|c|c|c|c|c|}
\hline & \multicolumn{2}{|c|}{$\begin{array}{c}\text { Total reported salt } \\
\text { intake } \\
(n 319) \\
\end{array}$} & \multicolumn{2}{|c|}{$\begin{array}{c}24 \mathrm{~h} \text { urinary } \mathrm{Na} \\
\text { excretion } \\
(n 517)\end{array}$} & \multicolumn{2}{|c|}{$\begin{array}{l}24 \mathrm{~h} \text { dietary recall } \\
(n 319)\end{array}$} & \multicolumn{2}{|c|}{$\begin{array}{l}\text { Na-FFQ } \\
(n 517)\end{array}$} & \multicolumn{2}{|c|}{$\begin{array}{c}\text { SSQ } \\
(n 517)\end{array}$} & \multicolumn{2}{|c|}{$\begin{array}{c}\text { DSQ } \\
(n 517)\end{array}$} \\
\hline & Mean & SD & Mean & SD & Mean & SD & Mean & SD & Mean & SD & Mean & SD \\
\hline \multicolumn{13}{|c|}{ Alcohol consumption } \\
\hline Yes & 11.9 & $6 \cdot 8$ & $11.5^{\star}$ & $5 \cdot 0$ & $3 \cdot 1^{*}$ & 3.0 & $1.0^{*}$ & 0.9 & 1.0 & $2 \cdot 2$ & $7 \cdot 2$ & $6 \cdot 1$ \\
\hline No & 10.7 & 5.7 & $10 \cdot 3^{*}$ & 4.4 & $2 \cdot 8^{*}$ & 2.6 & $0.7^{*}$ & $1 \cdot 1$ & 0.7 & 1.2 & $6 . \overline{7}$ & $5 \cdot 0$ \\
\hline \multicolumn{13}{|l|}{ Diabetes } \\
\hline Yes & $10 \cdot 8$ & $5 \cdot 6$ & $10 \cdot 9$ & 4.9 & $2 \cdot 6$ & $2 \cdot 2$ & $0.6^{*}$ & 0.6 & 0.7 & 1.3 & $8 \cdot 2^{*}$ & 6.5 \\
\hline No & $12 \cdot 0$ & 5.9 & 10.5 & 4.5 & 2.9 & 2.6 & $0.8^{*}$ & $1 \cdot 1$ & 0.7 & 1.5 & $6 \cdot 5^{*}$ & $5 \cdot 0$ \\
\hline \multicolumn{13}{|l|}{ Hypertension } \\
\hline Yes & $10 \cdot 6$ & $5 \cdot 1$ & $10 \cdot 7$ & 4.5 & $2 \cdot 7^{*}$ & $3 \cdot 1$ & $0.6^{*}$ & 0.7 & 0.7 & 1.3 & $7 \cdot 7^{\star}$ & $6 \cdot 2$ \\
\hline \multirow[t]{2}{*}{ No } & $11 \cdot 4$ & $6 \cdot 9$ & $10 \cdot 4$ & 4.5 & $3 \cdot 0^{*}$ & $2 \cdot 0$ & $0.9^{*}$ & $1 \cdot 2$ & 0.8 & 1.6 & $6 \cdot 0^{*}$ & $4 \cdot 3$ \\
\hline & $r$ & $P$ value & $r$ & $P$ value & $r$ & $P$ value & $r$ & $P$ value & $r$ & $P$ value & $r$ & $P$ value \\
\hline \multicolumn{13}{|c|}{ Systolic blood pressure } \\
\hline Total sample & 0.028 & 0.617 & 0.056 & 0.203 & -0.154 & 0.005 & -0.132 & 0.002 & -0.030 & 0.496 & 0.115 & 0.008 \\
\hline Normotensive & -0.046 & 0.603 & 0.014 & 0.839 & -0.143 & 0.103 & 0.029 & 0.658 & 0.051 & 0.443 & 0.004 & 0.955 \\
\hline Hypertensive & 0.043 & 0.554 & 0.074 & 0.214 & -0.056 & 0.446 & -0.085 & 0.152 & -0.078 & 0.189 & 0.088 & 0.135 \\
\hline \multicolumn{13}{|c|}{ Diastolic blood pressure } \\
\hline Total sample & 0.080 & 0.617 & 0.086 & 0.051 & 0.007 & 0.889 & 0.041 & 0.349 & 0.028 & 0.524 & 0.086 & 0.049 \\
\hline Normotensive & 0.029 & 0.738 & 0.115 & 0.083 & 0.094 & 0.286 & 0.178 & 0.007 & 0.103 & $0 \cdot 120$ & -0.030 & 0.649 \\
\hline Hypertensive & 0.101 & 0.167 & 0.041 & 0.486 & -0.001 & 0.994 & 0.037 & 0.531 & -0.006 & 0.917 & 0.105 & 0.077 \\
\hline \multicolumn{13}{|c|}{ Waist circumference } \\
\hline Male & 0.111 & 0.201 & 0.226 & 0.001 & 0.114 & 0.189 & 0.155 & 0.023 & 0.027 & 0.699 & 0.089 & 0.193 \\
\hline Female & 0.119 & 0.106 & 0.166 & 0.004 & -0.205 & 0.005 & -0.016 & 0.779 & 0.044 & 0.447 & 0.159 & 0.006 \\
\hline BMI & 0.070 & 0.210 & 0.155 & $<0.001$ & -0.028 & 0.610 & 0.071 & $0 \cdot 105$ & 0.032 & 0.455 & 0.083 & 0.058 \\
\hline
\end{tabular}

Na-FFQ, sodium FFQ; DSQ, discretionary-salt questionnaire; SSQ, seasoned-salt questionnaire, $r$, Spearman's correlation coefficient.

${ }^{*} P<0.05$ (Mann-Whitney $U$ test).

processed food with high $\mathrm{Na}$ content accounted for only about $7 \%$ of salt intake. Studies in Brazil using the same methodology with hypertensive and heart-failure patients observed the same pattern of salt intake ${ }^{(23,39,43)}$, being reinforced by data from the 2008-2009 Household Budget Survey within the general population that found a contribution of $74.4 \%$ from discretionary salt and salt-based condiments to overall salt intake ${ }^{(14)}$. This contrasts significantly with developed countries, where the main source is usually ultra-processed foods ${ }^{(40)}$. Although there are few studies on how the consumption of ultraprocessed foods varies within a population, this pattern seems to be associated, among other factors, with the relative affordability of ultra-processed foods ${ }^{(41,42)}$. 
Table 5 Multiple regression analysis of factors associated with $24 \mathrm{~h}$ urinary sodium excretion and total reported salt intake in the study population of adults and older people ( $n$ 517) aged 20-80 years, Artur Nogueira, São Paulo, Brazil, June-September 2016

\begin{tabular}{|c|c|c|c|c|}
\hline & \multirow[b]{2}{*}{ Coefficient } & \multicolumn{3}{|c|}{$95 \% \mathrm{Cl}$} \\
\hline & & Lower limit & Upper limit & $P$ value \\
\hline \multicolumn{5}{|l|}{$24 \mathrm{~h}$ urinary $\mathrm{Na}$ excretion } \\
\hline Age (ref. $=<65$ years) & -1.8855 & $-2 \cdot 8064$ & -0.9646 & $<0.0001$ \\
\hline Monthly family income (ref. => \$US 1900) & -0.4799 & $-1 \cdot 2320$ & 0.2722 & 0.2111 \\
\hline Waist circumference $($ ref. $=$ normal $) \dagger$ & $1 \cdot 2836$ & 0.4673 & $2 \cdot 1000$ & 0.0021 \\
\hline Hypertension (ref. $=$ no) $\ddagger$ & 0.2914 & -0.5419 & 1.1248 & 0.4931 \\
\hline Diabetes $($ ref. $=$ no $)$ & 0.4189 & -0.6787 & 1.5165 & 0.4544 \\
\hline Sex (ref. = women) & 2.7494 & 1.9412 & 3.5576 & $<0.0001$ \\
\hline \multicolumn{5}{|l|}{ Total reported salt intake } \\
\hline Age (ref. $=<65$ years) & -0.2079 & -1.8563 & 1.4406 & 0.8048 \\
\hline Monthly family income (ref. $=>$ \$US 1900) & 1.0139 & -0.2851 & 2.3129 & 0.1261 \\
\hline Waist circumference $($ ref. $=$ normal $) \dagger$ & 0.3637 & -1.0279 & 1.7554 & 0.6085 \\
\hline Hypertension (ref. = no) $\ddagger$ & 0.3835 & -1.0523 & 1.8192 & 0.6006 \\
\hline Diabetes $($ ref. $=$ no $)$ & 1.0278 & -0.9094 & 2.9650 & 0.2984 \\
\hline Sex (ref. = women) & 2.0464 & 0.6701 & 3.4228 & 0.0036 \\
\hline
\end{tabular}

Ref., reference category.

$\dagger$ Normal waist circumference defined as $\leq 88 \mathrm{~cm}$ (women) and $\leq 102 \mathrm{~cm}$ (men) ${ }^{(25)}$

$\ddagger$ Hypertension defined as self-reported hypertension or use of antihypertensive medicine.

Our data also indicated a positive and significant correlation between the biochemical measure and the sum of the self-reported methods of salt intake. Singly, the self-reported measures were positive and significantly correlated with $24 \mathrm{~h}$ urinary $\mathrm{Na}$ excretion, particularly the Na-FFQ, in the total sample and both sexes separately. Still, women presented more significant correlations than men among the methods for estimating salt intake, which could suggest that women were probably more precise in reporting their pattern of consumption than men.

Regarding the other sociodemographic variables, we observed that participants under age 65 years, those who were professionally active and those with higher family incomes had higher salt intakes according to $24 \mathrm{~h}$ urinary $\mathrm{Na}$ excretion. Furthermore, those under 65 years of age, with more than 5 years of schooling, professionally active and with higher monthly family incomes had higher salt intakes according the $24 \mathrm{~h}$ dietary recall and the Na-FFQ, but lower intakes according to the DSQ. Their total intake, however, was overall equivalent to that of their counterparts. Therefore, the main source of salt consumption for these individuals was ultra-processed foods, which can obviate the need for adding salt during meal preparation. Thus, health interventions for this population must focus on optimizing the consumption of foods prepared at home, replacing processed foods.

On the other hand, those who were older, with less schooling, not professionally active or with lower incomes - who consumed homemade meals more frequently and not ultra-processed foods - seemed to compensate for this lack by adding more salt to their meals to preserve the eating pleasure related to salt intake. This is important information in designing targeted interventions. Promoting the reduction of added salt could be less effective among younger people, those with more schooling, professionally active or with higher family incomes, because that is not their main source of dietary salt.

Concerning disease-related variables, participants with known chronic diseases, such as hypertension and diabetes, reported less consumption of salty foods as assessed by the Na-FFQ, although they added more salt during meal preparation, resulting in an overall intake similar to that of participants without chronic conditions. Thus, the interventions targeting these subgroups must emphasize reducing salt added to meals. However, participants who reported alcohol use presented higher salt intake, as seen in almost all assessment measures, reproducing previous findings ${ }^{(44)}$. The hypotheses proposed to explain this relationship are related to alcohol consumption influencing salt enjoyment and to the fact that alcoholic beverages and salty foods frequently go together ${ }^{(45-47)}$.

Regarding the relationship between salt intake and blood pressure levels, our results differ from those found in the literature $^{(48,49)}$ since, contrary to our expectations, we did not find a significant correlation between salt consumption and blood pressure levels. The lack of this relationship among the hypertensive adults in our study might be explained by use of antihypertensive medications, possibly introducing bias in the results. For the non-hypertensive participants, limited data collection might have contributed to the lack of correlation. The blood pressure measurement in the present study was based on the standardized technique advocated by the Brazilian Society of Cardiology ${ }^{(25)}$ but was assessed only once. There is a growing literature on the phenomenon of masked hypertension, defined as a 'clinical condition in which a patient's office blood pressure level is $<140 / 90 \mathrm{mmHg}$ but ambulatory or home blood pressure readings are in the hypertensive range ${ }^{, 50)}$. Its prevalence in the population is about one in seven or eight persons with a normal office blood pressure level. In fact, 
the International Consortium for Quality Research on Dietary Sodium/Salt (TRUE) ${ }^{(51)}$, formed to improve the quality of research on dietary salt, highlights that much of the controversy surrounding the association between dietary salt and increased blood pressure might be due to a lack of standardization of and quality in blood pressure measurement. Thus, in future studies, the use of multiple measures of blood pressure could be important to reducing measurement bias.

Another finding of the present study refers to the association between the anthropometric measures mainly waist circumference - and salt intake. We observed that men with greater waist circumference consumed more ultra-processed foods high in salt. In addition, women with greater waist circumference added more salt to their meals. Additionally, both sexes presented a positive correlation between waist circumference and $24 \mathrm{~h}$ urinary Na excretion. A recent meta-analysis showed that individuals who consumed higher amounts of salt evidenced a $4.75 \mathrm{~cm}$ larger waist circumference ${ }^{(52)}$. Other studies have also found positive correlations between salt intake and different measures of obesity or visceral obesity $^{(53-55)}$. Some authors have claimed that salt intake stimulates thirst and appetite, thus promoting energy intake ${ }^{(54,56)}$. These results call for special attention in assessing both salt intake and overall nutritional intake, especially among those individuals presenting overweight or obesity, to better design educational activities aimed at promoting a healthier salt intake.

The multivariate analyses revealed a relationship between waist circumference, age and sex with the variation in salt intake measured by $24 \mathrm{~h}$ urinary $\mathrm{Na}$ excretion. On the other hand, sex alone accounted for the variation in consumption based on the measurement of total reported salt intake. In fact, as demonstrated in other studies $^{(13,35,57-61)}$, the men presented a higher total consumption than the women according not only to $24 \mathrm{~h}$ urinary $\mathrm{Na}$ excretion, but also the self-report methods. Therefore, sex remains an important variable associated with salt intake for any measurement ${ }^{(13,35,57-61)}$. As for the age variable, other studies ${ }^{(62,63)}$ also observed that older individuals tend to have lower salt intake, which could be explained by wanting to have a better quality of diet.

The results of epidemiological studies shed light on the uniqueness of each population with respect to different patterns of health and health-related factors. Consequently, they inform the design of tailored and more precise interventions. Moreover, larger interventions or intervention policies on salt intake must rest on the characterization of its consumption profile in the targeted population. A survey conducted in over fortyfive countries ${ }^{(64)}$ aimed at identifying what approaches governments were taking to monitor salt intake. It found that the majority of the thirty countries reporting formal government salt monitoring activities were high-income countries and that less than half of them used $24 \mathrm{~h}$ urinary $\mathrm{Na}$ excretion to assess salt intake. In addition, only two of them were developing countries.

To the best of our knowledge, the present study was one of the first population studies using the gold standard measure of salt intake, i.e. $24 \mathrm{~h}$ urinary $\mathrm{Na}$ excretion, combined with self-report methods. Due to the complexity of dietary salt behaviour, the combination of self-report (Na-FFQ, 24 h dietary recall, DSQ, SSQ) and biochemical methods (24h urinary $\mathrm{Na}$ excretion) is highly recommended $^{(65,66)}$ but rarely done, especially in populationbased studies ${ }^{(66)}$, due to the economic and technical difficulties. Thus, our study makes a unique contribution in furthering Brazilian policies for monitoring salt intake. Besides being conducted in a small town, the present study was the first effort in the country to perform an extensive and detailed characterization of salt intake in the adult and elderly population. This study design can be reproduced in larger towns and regions to obtain a global portrait of salt consumption in Brazil's population. With respect to the literature, the study provides important information about salt intake in developing countries.

Nevertheless, the study had some limitations. First, it was not possible to quantify salt intake from the $24 \mathrm{~h}$ dietary recall for 198 out of the 517 participants due to restricted availability of the nutritional software for research use. Regardless, as no differences regarding sociodemographic and disease-related characterization were observed between this sub-sample and the whole group, the results seem to reflect the overall pattern of intake according this method for the studied population. Other limitations relate to: the absence of a reliable biochemical technique to validate completeness of the $24 \mathrm{~h}$ urine collections due to the inadequate funds; not questioning patients diagnosed with hypertension about their restriction of salt intake; measuring blood pressure only once in the study; and the reliability of the dietary recall methods used with an older population.

Lastly, our results confirm the present study's importance in providing a profile of the salt intake of a metropolitan population. Some interventions could be proposed to promote a healthier approach to dietary salt in the studied population. Moreover, the study can inform the design of larger studies, including in larger Brazilian towns in different regions, and thereby better support decision making on the national level regarding public policies significantly impacting the cardiovascular health of the Brazilian population. According to Webb et al. ${ }^{(67)}$, a $10 \%$ reduction in salt consumption over a 10 -year period could avoid approximately $5 \cdot 8$ million disability-adjusted life years per year related to CVD.

\section{Conclusion}

The present study combined self-reported and biochemical measures, resulting in characterization of the salt intake and 
identifying its sources of consumption among adults and older people of the town of Artur Nogueira, Brazil. The findings reveal a high overall salt intake in the studied population, with the salt added during cooking as the main source. Salt intake also varied according to other factors such as sex, age and waist circumference. Thus, future research on interventions targeting the reduction of salt consumption can take account of the various intake patterns according to sociodemographic and disease-related factors.

\section{Acknowledgements}

Financial support: This research received no specific grant from any funding agency in the public, commercial or not-for-profit sectors. Conflict of interest: None. Authorship: M.S.P., M.E.C. and M.-C.B.J.G. designed the research; M.S.P. and M.E.C. conducted the research; M.S.P., M.E.C., H.C.O. and M.-C.B.J.G. analysed the data; M.S.P., M.E.C., T.M.S.-J., C.R. and M.-C.B.J.G. wrote the paper. All authors read and approved the final manuscript. Ethics of buman subject participation: This study was conducted according to the guidelines laid down in the Declaration of Helsinki and all procedures involving human subjects were approved by the University of Campinas (UNICAMP) Ethics Committee (protocol number 52955316.9.0000.5404). Written informed consent was obtained from all subjects.

\section{References}

1. Strazzullo P, D'Elia L, Kandala NB et al. (2009) Salt intake, stroke, and cardiovascular disease: meta-analysis of prospective studies. BMJ 339, b4567.

2. Aburto NJ, Ziolkovska A, Hooper L et al. (2013) Effect of lower sodium intake on health: systematic review and metaanalyses. BMJ 346, f1326.

3. He FJ, Li J \& MacGregor GA (2013) Effect of longer term modest salt reduction on blood pressure: Cochrane systematic review and meta-analysis of randomized trials. BMJ 346, f1325.

4. Mozaffarian D, Singh GM \& Powles J (2014) Sodium and cardiovascular disease. $N$ Engl J Med 371, 2138-2139.

5. Graudal N, Hubeck-Graudal T, Jürgens G et al. (2015) The significance of duration and amount of sodium reduction intervention in normotensive and hypertensive individuals: a meta-analysis. Adv Nutr 13, 169-177.

6. Johnson C, Raj TS, Trudeau L et al. (2015) The science of salt: a systematic review of clinical salt studies 2013 to 2014. J Clin Hypertens (Greenwich) 17, 401-411.

7. Lim SS, Vos T, Flaxman AD et al. (2012) A comparative risk assessment of burden of disease and injury attributable to 67 risk factors and risk factor clusters in 21 regions, 1990-2010: a systematic analysis for the Global Burden of Disease Study 2010. Lancet 380, 2224-2260.

8. Anderson CA, Appel LJ, Okuda N et al. (2010) Dietary sources of sodium in China, Japan, the United Kingdom, and the United States, women and men aged 40 to 59 years: the INTERMAP study. J Am Diet Assoc 110, 736-745.

9. Powles J, Fahimi S, Micha R et al. (2013) Global, regional and national sodium intakes in 1990 and 2010: a systematic analysis of $24 \mathrm{~h}$ urinary sodium excretion and dietary surveys worldwide. BMJ Open 3, e003733.
10. World Health Organization (2016) SHAKE the salt habit. The SHAKE technical package for salt reduction. http://apps. who.int/iris/bitstream/10665/250135/1/9789241511346-eng .pdf (accessed June 2017)

11. Cogswell ME, Maalouf J, Elliott $P$ et al. (2015) Use of urine biomarkers to assess sodium intake: challenges and opportunities. Annu Rev Nutr 35, 349-387.

12. Trinquart L, Johns DM \& Galea S (2016) Why do we think we know what we know? A metaknowledge analysis of the salt controversy. Int J Epidemiol 45, 251-260.

13. Rodrigues SL, Souza Júnior PR, Pimentel EB et al. (2015) Relationship between salt consumption measured by 24-h urine collection and blood pressure in the adult population of Vitória (Brazil). Braz J Med Biol Res 48, 728-735.

14. Sarno F, Claro RM, Levy RB et al. (2013) Estimativa de consumo de sódio pela população brasileira, 2008-2009. Rev Saude Publica 47, 571-578.

15. Holbrook JT, Patterson KY, Bodner JE et al. (1984) Sodium and potassium intake and balance in adults consuming selfselected diets. Am J Clin Nutr 40, 786-793.

16. Ji C, Sykes L, Paul C et al. (2012) Systematic review of studies comparing 24-hour and spot urine collections for estimating population salt intake. Rev Panam Salud Publica 32, 307-315.

17. McLean RM (2014) Measuring population sodium intake: a review of methods. Nutrients $\mathbf{6}, 4651-4662$.

18. World Health Organization \& Pan American Health Organization (2010) Protocol for population level sodium determination in 24-hour urine samples. Prepared by: WHO/PAHO Regional Expert Group for Cardiovascular Disease Prevention through Population-wide Dietary Salt Reduction (Sub-group for Research and Surveillance). http://www.paho.org/hq/index.php?option=com_docman\& task $=$ doc_view\&gid $=21488 \& I t e m i d=270 \& l a n g=e n \quad$ (accessed June 2017).

19. Brazilian Institute of Geography and Statistics (2016) Town of Artur Nogueira, 2016. http://www.cidades.ibge.gov.br/ xtras/temas.php?lang=\&codmun=350380\&idtema=16\&sear $\mathrm{ch}=$ sao-paulolartur-nogueiralsintesedasinmuciformacoes (accessed April 2016).

20. Cochran WG (1977) Sampling Techniques, 3rd ed. New York: John Wiley \& Sons.

21. Piovesana PM, Sampaio KL \& Gallani MCBJ (2012) Association between taste sensitivity and self-reported and objective measures of salt intake among hypertensive and normotensive individuals. ISRN Nutr 2013, 301213.

22. De Freitas Agondi R, Cornélio ME, Rodrigues RMC et al. (2014) Implementation intentions on the effect of salt intake among hypertensive women: a pilot study. Nurs Res Pract 2014, 196410.

23. Cornélio ME, Godin G, Rodrigues RCM et al. (2016) Effect of a behavioral intervention of the SALdável program to reduce salt intake among hypertensive women: a randomized controlled pilot study. Eur J Cardiovasc Nurs 15, e85-e94.

24. Faludi AA, Izar MCO, Saraiva JFK et al. (2017) Update of the Brazilian Guideline on Dyslipidemias and Prevention of Atherosclerosis - 2017. Arq Bras Cardiol 109, 2 Suppl. 1, 1-76.

25. Brazilian Society of Hypertension, Brazilian Society of Cardiology \& Brazilian Society of Nephrology (2010) VI Brazilian Guidelines for Hypertension. http://publicacoes. cardiol.br/consenso/2010/Diretriz_hipertensao_ERRATA.pdf (accessed February 2018).

26. World Health Organization (2011) Waist Circumference and Waist-Hip Ratio: Report of a WHO Expert Consultation, Geneva, 8-11 December 2008. http://apps.who.int/iris/ bitstream/10665/44583/1/9789241501491_eng.pdf (accessed June 2017).

27. Pelleg A \& Levy GB (1975) Determination of $\mathrm{Na}^{+}$and $\mathrm{K}^{+}$in urine with ion-selective electrodes in an automated analyzer. Clin Chem 21, 1572-1574. 
28. He FJ \& MacGregor GA (2010) Reducing population salt intake worldwide: from evidence to implementation. Prog Cardiovasc Dis 52, 363-382.

29. Elliott P \& Brown I (2007) Sodium intakes around the world. Background document prepared for the Forum and Technical meeting on Reducing Salt Intake in Populations (Paris 5-7th October 2006). http://www.who.int/dietphysicalactivity/ Elliot-brown-2007.pdf (accessed June 2018).

30. Center for Studies and Research on Foods (2011) Brazilian Table of Food Composition. Campinas, SP: NEPA, UNICAMP.

31. Ferreira-Sae MC, Gallani MC, Nadruz W et al. (2009) Reliability and validity of a semi-quantitative FFQ for sodium intake in low-income and low-literacy Brazilian hypertensive subjects. Public Health Nutr 12, 2168-2173.

32. Monteiro CA, Levy RB, Claro RM et al. (2010) A new classification of foods based on the extent and purpose of their processing. Cad Saude Publica 26, 2039-2049.

33. Molina MCB, Cunha RS, Herkenhoff LF et al. (2003) Hypertension and salt intake in an urban population. Rev Saude Publica 37, 743-750.

34. Gill F (2000) Generalized Linear Models: A Unified Approach. Sage University Papers Series on Quantitative Applications in the Social Sciences 07-134. Thousand Oaks, CA: SAGE Publications, Inc.

35. Johnson C, Mohan S, Rogers K et al. (2017) Mean dietary salt intake in urban and rural areas in India: a population survey of 1395 persons. J Am Heart Assoc 6, e004547.

36. World Health Organization (2014) Global status report on noncommunicable diseases 2014. http://apps.who.int/iris/ bitstream/10665/148114/1/9789241564854_eng.pdf (accessed June 2017).

37. Swanepoel B, Schutte AE, Cockeran M et al. (2016) Sodium and potassium intake in South Africa: an evaluation of 24hour urine collections in a white, black, and Indian population. J Am Soc Hypertens 10, 829-837.

38. Land MA, Webster J, Christoforou A et al. (2014) Salt intake assessed by $24 \mathrm{~h}$ urinary sodium excretion in a random and opportunistic sample in Australia. BMJ Open 4, e003720.

39. Perin MS, Cornélio ME, Rodrigues RCM et al. (2013) Characterization of salt consumption among hypertensives according to socio-demographic and clinical factors. Rev Lat Am Enfermagem 21, 1013-1021.

40. Harnack LJ, Cogswell ME, Shikany JM et al. (2017) Sources of sodium in US adults from 3 geographic regions. Circulation 135, 1775-1783.

41. Moubarac JC, Claro RM, Baraldi LG et al. (2013) International differences in cost and consumption of ready-toconsume food and drink products: United Kingdom and Brazil, 2008-2009. Glob Public Health 8, 845-856.

42. Adams J \& White M (2015) Characterisation of UK diets according to degree of food processing and associations with socio-demographics and obesity: cross-sectional analysis of UK National Diet and Nutrition Survey (2008-12). Int J Behav Nutr Phys Act 12, 160.

43. Agondi RD, Gallani M, Rodrigues RCM et al. (2011) Relationship between beliefs regarding a low salt diet in chronic renal failure patients on dialysis. J Ren Nutr 21, 160-168.

44. Mattes RD \& DiMeglio D (2001) Ethanol perception and ingestion. Physiol Behav 72, 217-229.

45. Caton SJ, Ball M, Ahern A et al. (2004) Dose-dependent effects of alcohol on appetite and food intake. Physiol Behav 81, 51-58.

46. Choi KH, Park MS, Kim JA et al. (2015) Associations between excessive sodium intake and smoking and alcohol intake among Korean men: KNHANES V. Int J Environ Res Public Health 12, 15540-15549.

47. Lampuré A, Schlich P, Deglaire A et al. (2015) Sociodemographic, psychological, and lifestyle characteristics are associated with a liking for salty and sweet tastes in French adults. $J$ Nutr 145, 587-594.
48. Arcand J, Wong MMY, Santos JA et al. (2017) More evidence that salt increases blood pressure and risk of kidney disease from the Science of Salt: a regularly updated systematic review of salt and health outcomes (April-July 2016). J Clin Hypertens (Greenwich) 19, 813-823.

49. He FJ, Pombo-Rodrigues S \& Macgregor GA (2014) Salt reduction in England from 2003 to 2011: its relationship to blood pressure, stroke and ischaemic heart disease mortality. BMJ Open 4, e004549.

50. Papadopoulos DP \& Makris TK (2007) Masked hypertension definition, impact, outcomes: a critical review. J Clin Hypertens (Greenwich) 9, 956-963.

51. TRUE Consortium (2017) Recommended standards for assessing blood pressure in human research where blood pressure or hypertension is a major focus. J Clin Hypertens (Greenwich) 19, 108-113.

52. Moosavian SP, Haghighatdoost F, Surkan PJ et al. (2016) Salt and obesity: a systematic review and meta-analysis of observational studies. Int J Food Sci Nutr 68, 265-277.

53. Hoffmann IS \& Cubeddu LX (2009) Salt and the metabolic syndrome. Nutr Metab Cardiovasc Dis 19, 123-128.

54. Oh SW, Han KH, Han SY et al. (2015) Association of sodium excretion with metabolic syndrome, insulin resistance, and body fat. Medicine (Baltimore) 94, e1650.

55. Thuesen BH, Toft U, Buhelt LP et al. (2015) Estimated daily salt intake in relation to blood pressure and blood lipids: the role of obesity. Eur J Prev Cardiol 22, 1567-1574.

56. He FJ, Marrero NM \& MacGregor GA (2008) Salt intake is related to soft drink consumption in children and adolescents: a link to obesity? Hypertension 51, 629-634.

57. Schoen T, Blum J, Paccaud F et al. (2013) Factors associated with 24-hour urinary volume: the Swiss salt survey. BMC Nephrol 14, 246.

58. Cornejo K, Pizarro F, Atalah E et al. (2014) Assessment of dietary intake and urinary excretion of sodium and potassium in adults. Rev Med Chil 142, 687-695.

59. Ogna A, Forni Ogna V, Bochud M et al. (2014) Prevalence of obesity and overweight and associated nutritional factors in a population-based Swiss sample: an opportunity to analyze the impact of three different European cultural roots. Eur J Nutr 53, 1281-1290.

60. Polonia J, Martins L, Pinto F et al. (2014) Prevalence, awareness, treatment and control of hypertension and salt intake in Portugal: changes over a decade. The PHYSA study. J Hypertens 32, 1211-1221.

61. Nowson C, Lim K, Grimes C et al. (2015) Dietary salt intake and discretionary salt use in two general population samples in Australia: 2011 and 2014. Nutrients 7, 10501-10512.

62. Assumpção D, Domene SMA, Fisberg RM et al. (2016) Social and demographic inequalities in diet quality in a population-based study. Rev Nutr 29, 151-162.

63. Hiza HAB, Casavale KO, Guenther PM et al. (2012) Diet quality of Americans differs by age, sex, race/ethnicity, income, and education level. J Acad Nutr Diet 113, 297-306.

64. Hawkes C \& Webster J (2012) National approaches to monitoring population salt intake: a trade-off between accuracy and practicality? PLoS One 7, e46727.

65. Shim JS, Oh K \& Kim HC (2014) Dietary assessment methods in epidemiologic studies. Epidemiol Health 36, e2014009.

66. Pan American Health Organization (2013) Salt-Smart Americas: A Guide for Country-Level Action. http://www. paho.org/hq/index.php?option=com_docman\&task=doc_ view\&gid=21554\&Itemid=270\&lang=en (accessed June 2018).

67. Webb M, Fahimi S, Singh GM et al. (2017) Cost effectiveness of a government supported policy strategy to decrease sodium intake: global analysis across 183 nations. BMJ 356, i6699. 